\title{
Emergency department problems raised at Sinclair inquest
}

$\mathrm{S}$ ystemic racism, a chronic shortage of nursing resources and a culture of indifference among some health professionals are among the factors being discussed in an inquest into the death of an Aboriginal man who spent 34 hours unattended in a Winnipeg, Manitoba, emergency department.

Brian Sinclair, a double-amputee with a history of substance abuse, died in September 2008 in the emergency department waiting room of Winnipeg's Health Sciences Centre. An autopsy later found that Sinclair, 45, had a bladder infection brought on by a blocked catheter.

The testimony, which began in August, has revealed that Sinclair arrived at hospital with a note from a walk-in clinic explaining his condition. Despite that, he was never triaged and was instead sent to the waiting room.

During his time in the waiting room, testimony confirmed, Sinclair had been observed on at least 17 occasions. In several instances, security staff or other patients in the waiting room raised concerns about his condition to nursing staff, but were ignored.

In what was the most alarming detail to come out of the first stage of the inquest, coroners estimated Sinclair had been dead for between two and seven hours before someone noticed.

The Winnipeg Police Service would ultimately launch a criminal investigation into Sinclair's death. On the advice of an independent prosecutor, no criminal charges were laid.

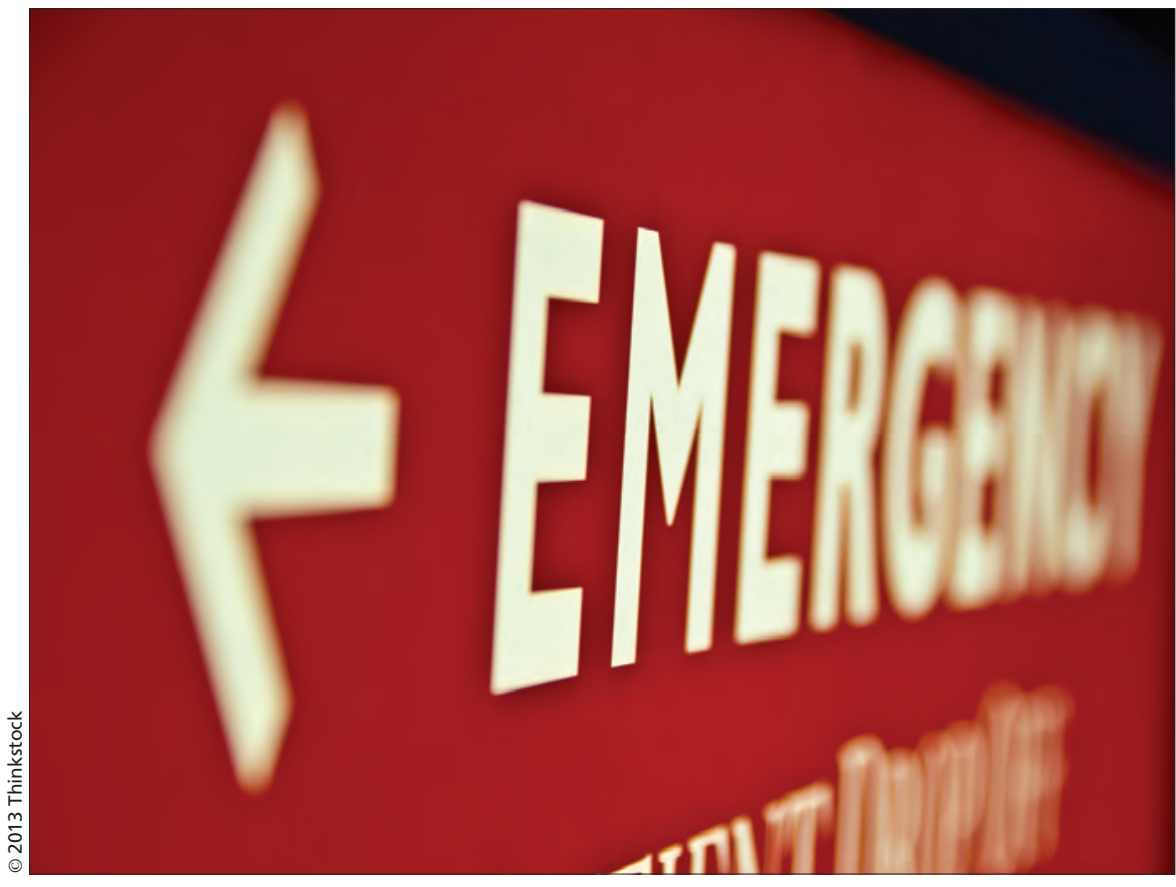

An excessively busy and understaffed emergency department has been cited as a contributing factor in an inquiry into a death in Manitoba.

"The testimony to date adds up to a fairly disturbing factual record," says Zbogar. "I don't think anyone is suggesting that it was only race. But you cannot separate the way he was treated from the fact that he was Aboriginal."

Other witnesses refuted the idea that racism was the principal factor. Dr. Thambirajah Balachandra, Manitoba's chief medical examiner and a key witness in the first phase of the inquest, testified that problems with the organization and culture of the emergency department were at the root of this tragedy.

\section{Coroners estimated Sinclair had been dead for between two and seven hours before someone noticed.}

Much of the testimony to date has focused on the issue of racism. Vilko Zbogar, lead lawyer for the Sinclair family, has alleged the negligence in this case was a result of who Sinclair was: an impoverished Aboriginal man with a long list of health problems related to chronic solvent abuse.
"Even if Snow White had gone there," Dr. Balachandra testified, "she would have got the same treatment under the same circumstances."

Testimony from senior nursing staff on duty at the time of Sinclair's death indicated that the emergency department was not only busier than usual, it was also seriously understaffed. A combination of chronic understaffing and sickness had reduced the total complement in the emergency department by five nurses.

The understaffing and aboveaverage patient load meant that a nurse specifically tasked to check on patients in the waiting room was reassigned to other duties. This position was created in 2003 following another death in the emergency department.

Although it appears staffing was an issue in this case, that has not stopped the Winnipeg Regional Health Authority from examining deeper issues.

Arlene Wilgosh, president and CEO of the health authority, says she believes there are issues related to the culture of care that must be examined during the inquest. Specifically, there is concern that nursing staff did not heed the calls of security guards and other patients who observed Sinclair's deteriorating condition, she adds.

"Just about everybody we talk to acknowledges that there is a cultural issue here," says Wilgosh. "And we know that more resources alone are not going to fix it." - Dan Lett, Winnipeg, Man.

CMAJ 2013. DOI:10.1503/cmaj.109-4633 